\title{
IMPLEMENTASI FINITE STATE MACHINE SEBAGAI KONTROL UNTUK NON PLAYER CHARACTER PADA GAME "LASTRI AND THE LAST TREE"
}

\author{
Fikriadi Sakrani, Suryo Adi Wibowo, Febriana Santi Wahyuni \\ Program Studi Teknik Informatika S1, Fakultas Teknologi Industri \\ Institut Teknologi Nasional Malang, Jalan Raya Karanglo km 2 Malang, Indonesia \\ 1318078@scholar.itn.ac.id
}

\begin{abstract}
ABSTRAK
Pada saat ini game merupakan sarana hiburan yang paling diminati oleh setiap kalangan,mulai dari anak anak, remaja, maupun orang dewasa. Game tidak hanya berfungsi sebagai media hiburan saja, beberapa pesan atau pelajaran bisa didapatkan dari bermain game, seperti bagaimana perjuangan suatu karakter yang tidak pernah menyerah menghadapi rintangan atau musuh - musuhnya demi mencapai tujuannya, melatih kemampuan berfikir dalam mengambil keputusan dalam situasi yang sulit, serta dapat mengasah kereatifitas.

Dalam perancangan game ini, penulis menggunakan game engine Unity $3 D$ dengan bahasa pemrograman C\#. Dalam pembuatan game ini menerapkan metode kecerdasan buatan Finite State Machine yang menggunakan menentukan aksi dengan jarak player ke musuh. FSM memiliki prinsip kerja yang terdiri dari tiga hal berikut : State (Keadaan), Event (Kejadian), Action (Aksi) sehingga digunakan sebagai metode pada game.

Dari pengujian yang telah dilakukan hasil dari kecerdasan buatan FSM (Finite State Machine) pada game Adventure "Lastri And The Last Tree" ini karakter NPC (Non Playable Character) dapat mendeteksi keberadaan player untuk menentukan aksi serangan dari musuh, fungsi dari setiap tombol control player berjalan dengan sangat baik. AI menggunakan FSM (Finite State Machine) didapat hasil yang sesuai, seperti musuh dapat bergerak dengan otomatis sesuai dengan kecederdassan buatan yang diterapkan, dan mendapatkan timbal balik yang cukup baik dari para pengguna.
\end{abstract}

Kata kunci : Finite State Machine, Hutan, NPC, game Adventure, kecerdasan buatan, Unity 3D.

\section{PENDAHULUAN}

Pada masa pandemi covid-19 setiap orang diharuskan untuk tetap tinggal dirumah demi mengurangi penyebaran virus tersebut. Tentu saja hanya berdiam diri dapat menimbulkan kejenuhan bagi setiap orang, maka dibutuhkan beberapa aktifitas kecil atau hiburan saat berada dirumah seperti olahraga ringan, menonton, maupun bermain game. saat ini game merupakan sarana hiburan yang paling diminati oleh setiap kalangan, mulai dari anak - anak, remaja, maupun orang dewasa. Tentu setiap kalangan tersebut memiliki alasan dan selera masing - masing tentang jenis atau genre game yang dimainkan. Namun dalam sebuah game tidak hanya berfungsi sebagai media hiburan saja, beberapa pesan atau pelajaran bisa didapatkan dari bermain game, seperti bagaimana perjuangan suatu karakter yang tidak pernah menyerah menghadai rintangan atau musuh musuhnya demi mencapai tujuannya, melatih kemampuan berfikir dalam mengambil keputusan dalam situasi yang sulit, serta dapat mengasah kereatifitas.

Game sendiri memiliki berbagai macam genre, dapat dibedakan dari beberapa jenis, yaitu platform, dimensi, dan genre dari game itu sendiri. berdasarkan genre game dibedakan menjadi beberapa jenis, yaitu Game Srtategi (Strategy Game), Role Playing Game (RPG), Game Olahraga (Sport Game), Simulasi Kendaraan (Vehicles Game), Game Petualangan (Adventure Game), Game Puzzle (Puzzle Game), dan Game Aksi (Action Game). (Tanjung, 2000)
Dalam sebuah game petualangan terdapat sebuah cerita tentang game dan beberapa kakrakter seperti tokoh utama, musuh, dan bos. Dari karakter tersebut, selain tokoh utama atau player dua karakter yang lain yaitu musuh dan bos membutuhkan kecerdasan buatan atau biasa disebut AI (Artificial Intelligence) untuk bisa berinteraksi dengan player. Penggunaan metode FSM (Finite State Machine) pada game digunakan untuk mendukung interaksi antara tokoh utama dengan musuh maupun bos. FSM memiliki prinsip kerja yang terdiri dari tiga hal berikut : State (Keadaan), Event (Kejadian), Action (Aksi) sehingga digunakan sebagai metode pada game.

Game Lastri And The Last Tree merupakan game petualangan yang menceritakan tentang kebakaran hutan yang sering terjadi dan sebuah karakter bernama lastri sebagai karakter yang dikontrol oleh pemain yang masuk kedalam hutan untuk mengetahui penyebab terjadinya kebakaran hutan tersebut. Ternyata penyebabnya adalah sekumpulan orang yang telah bermutasi menjadi zombie yang telah hilang kesadaran dan membakar hutan. Lastri berusaha mengalahkan para zombie untuk menyelamatkan satu titik yang belum terbakar didalam hutan. Metode kecerdasan buatan yang digunakan pada game Lastri And The Last Tree adalah FSM (Finite State Machine) yang berfungsi untuk mengontrol NPC (Non Playable Character) yaitu karakter yang digunakan sebagai musuh dan digerakkan oleh kecerdasan buatan. Dari pemaparan diatas penulis ingin mengimplementasikan FSM 
(Finite State machine) ke dalam pembuatan sebuah game berjudul "Lastri And The Last Tree" yang merupakan game petualngan 2 dimensi dengan jenis Sidescrolling mengunakan unity3d sebagai game engine.

\section{TINJAUAN PUSTAKA}

\subsection{Penelitian Terdahulu}

Dalam penyusunan proposal skripsi ini, penulis sedikit banyak terinspirasi dan mereferensi dari penelitian - penelitian sebelumnya yang berkaitan dengan latar belakang masalah pada judul skripsi ini. Adapun penelitian yang berhubungan dengan judul skripsi ini antara lain yaitu :

Penelitian yang dilakukan oleh Irawan, J.D, dkk, 2015 berjudul "Pelatihan Pembuatan Game Menggunakan Greenfoot", dalam penelitian ini menyebutkan bahwa pembuatan game dengan menggunakan greenfoot merupakan salah satu cara untuk belajar pemrograman mudah dipahami karena hanya memerlukan sedikit perintah yang ditambahkan untuk membuat sebuah game.(Irawan, J.D, dkk, 2015)

Penelitian yang dilakukan oleh Wahyuni F.S dan Mantja S.N, 2016 berjudul "Penerapan Algoritma A* Untuk Pencarian Rule Terdekat Pada Permainan Berbasis Ubin (Tile Base Game) ", penggunaan Kecerdasan Buatan (Artificial Intelligence) pada sebuah permainan bertujuan untuk membuatnya lebih menarik. (Wahyuni F.S dan Mantja S.N, 2016)

Penelitian oleh Arif, Y.M dan Hariadi, M, pada tahun 2012 yang berjudul "Analisis Penggunaan Algoritma Breadth First Search Dalam Konsep Artificial Intellegencia" Artificial Intelligencia merupakan suatu konsep pemetaan suatu bahasa pemrograman yang dapat membuat suatu kesimpulan berdasarkan pemetaan yang telah dilakukan didalam pemrograman. Dalam hal ini, banyak metode yang dapat digunakan dan dimanfaatkan untuk menyelesaikan permasalahan tersebut. Penelitian ini menjelaskan tentang cara menerapkan kecerdasan buatan mencari solusi permasalahan teko air dengan 2 buah kendi dan menampilkan semua langkah langkah yang dapat diambil untuk mendapatkan solusi atau volume air yang diinginkan.Perangkat lunak dapat mencari solusi terpendek dari permasalahan teko air karena menggunakan metode pencarian melebar pertama (breadthfirst search). ( Arif, Y.M. dan Hariadi, M, 2012)

Dua NPC bisa saling membantu dalam menjalankan strategi menyerang terhadap musuh. Penelitian ini menjelaskan tentang bagaimana membuat strategi menyerang yang dilakukan oleh NPC dengan menggunakan Hierarchy Finite State Machine untuk mendesain perilaku. Dua NPC yang dimaksud adalah NPC Scout yang bertugas memancing serangan musuh, dan NPC Sniper yang bertugas memberikan back up serangan dari jarak jauh. Selanjutnya digunakan logika fuzzy untuk menentukan respon perilaku terhadap kondisi yang dihadapi. Perilaku yangdimaksud adalah menyerang brutal, menyerang, bertahan dan melarikan diri. Masing-masing perilaku diuji cobakan dalam game First Person Shooter menggunakan Torque Game Engine. Dalam simulasi game terjadi respon perubahan perilaku masing-masing NPC terhadap kondisi yang dihadapi.( Arif, Y.M. dan Hariadi, M, 2012)

Penelitian yang dilakukan oleh Pratama, 2014 berjudul "Game Adventure Misteri Kotak Pandora" penelitan ini mejelaskan tenang penerapan game adventure berbasis dekstop menggunakan software Unity3D dalam penelitian ini juga menjelaskan tentang berbagai macam genre game yang ada pada saat ini, khusus nya untuk game adventure. (Pratama, 2014)

\subsection{Game}

Game pada dasarnya bersifat hiburan karena jika pengguna memainkan game maka akan terasa menyenangkan. Dalam era saat ini, game disajikan dengan kualitas visualisasi yang cukup canggih karena didukung oleh teknologi sehingga pemain lebih interkatif sesuai kemaunnya sendiri dan pemain terasa hidup dalam game tersebut. Maka bisa disebutkan bahwa game berkembang beriringan dengan teknologi. (Pratama, 2014)

\subsection{Jenis Game}

Berdasarkan dimensi dari objek - objeknya, game dapat dibagi menjadi beberapa jenis, diantaranya:

1. Game 2D

2. Game 2.5D

3. Game 3D

Genre pada suatu game memperlihatkan pola umum tantangan dari game tersebut. Dengan perkembangan informasi seperti sekarang, genre dari game masih terus berkembang, sebagai contoh simulasi menari (dance simulation) yang diperkenalkan oleh desainer game dari Jepang. Namun secara umum game dapat dibagi menjadi beberapa jenis berdasarkan genre yang diterapkannya, yaitu:
1. Strategy Games (Game Strategi)
2. Role-Playing Games (RPG)
3. Sports Games (Game Olahraga)
4. Vehicles Simulation (Simulasi Kendaraan)
5. Adventure Games (Game Petualangan)
6. Puzzle Games (Game Puzzle)
7. Action Games (Game Aksi)

\subsection{AI (Artificial intelligence)}

Artificial Intelligence atau kecerdasan buatan termasuk bidang ilmu yang relative muda. Pada tahun 1950-an para ilmuwan dan peneliti mulai memikirkan bagaimana caranya agar mesin dapat melakukan pekerjaannya seperti yang bias dikerjakan oleh manusia. Alan Turing, seorang matematikawan dari 
Inggris pertama kali mengusulkan adanya pengujian untuk melihat bias tidaknya sebuah mesin dikatakan cerdas. Hasil pengujian tersebut kemudian dikenal dengan Turing Test, di mana mesin tersebut menyamar seolah-olah sebagai seseorang di dalam suatu permainan yang mampu memberikan respon terhadap serangkaian pertanyaan yang diajukan.

Kecerdasan buatan atau Artificial Intelligence itu sendiri dimunculkan oleh seorang professor dari Massachusetts Institute of Technology yang bernama John McCarthy pada tahun 1956 pada Darmouth Conference yang dihadiri oleh para peneliti AI. Pada konferensi tersebut juga didefinisikan tujuan utama dari kecerdasan buatan, yaitu mengetahui dan memodelkan proses-proses berpikir manusia dan mendesain mesin agar dapat menirukan kelakuan manusia tersebut.(Wijaya, 2013)

\subsection{FSM (Finite State Machine)}

Finite State Machine (FSM) adalah sebuah metodologi perancangan sistem kontrol yang menggambarkan tingkah laku atau prinsip kerja sistem dengan menggunakan tiga hal berikut: State (Keadaan), Event (kejadian) dan action (aksi). Sebagai sebuah metodologi perancangan sistem kontrol, penerapan FSM telah banyak diterapkan pada perangkat lunak, khususnya pada game. (Rahadian, 2016).

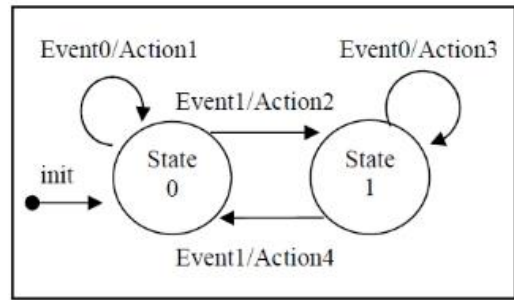

Gambar 2.1 Diagram state sederhana (Sumber : Setiawan, 2006)

Gambar 2.1 memperlihatkan FSM dengan dua buah state dan dua buah input serta empat buah output yang berbeda seperti terlihat pada gambar, ketika sistem mulai dihidupkan, sistem akan bertransisi menuju State0, pada keadaan ini sistem akan menghasilkan Action1 jika terjadi masukan Event0, sedangkan jika terjadi Event 1 maka Action 2 akan dieksekusi kemudian sistem selanjutnya bertransisi ke keadaan State 1 dan seterusnya.

Salah satu alternatif implementasi FSM adalah menggunakan pemrograman berorientasi objek (Object Oriented Programming) atau yang sering disingkat sebagai OOP (Wijaya, 2010). Kelebihan penggunaan OOP pada FSM adalah fleksibilitasnya yang tinggi dan pemeliharaannya yang mudah baik pada sistem yang sederhana, menengah, maupun sistem yang kompleks. Selain itu juga mendapatkan manfaat dari salah satu kelebihan OOP yaitu penggunaan kembali kode yang telah diketik (code reusability) sehinga pengetikan kode menjadi lebihmsedikit (Wijaya, 2010).

Transisi keadaan ini umumnya juga disertai oleh aksi yang dilakukan oleh system ketika menanggapi masukan yang terjadi. Aksi yang dilakukan tersebut dapat berupa aksi yang sederhana atau melibatkan rangkaian proses yang relative kompleks. Berdasarkan sifatnya, metode ini sangat cocok untuk digunakan sebagai basis perancangan perangkat lunak pengendalian yang bersigat reaktif dan real time. Salah satu keuntungan nyata pengguna finite state machine adalah kemampuannya dalam mendekomposisi aplikasi yang relative besar dengan hanya menggunakan sejumlah item state. Selain uyntuk bidang control, penggunaan metode ini pada kenyaanya juga umum digunakan sebagai basis untuk perancangan protocol-protocol komunikasi.

Selain itu metode ini juga dapat digunakan untuk perancangan perangkat lunak game, aplikasi web dan sebagainya. Dalam bahasa pemograman procedural seperti $\mathrm{C}$, metode finite state machine ini umumnya direlasikan dengan menggunakan statement control switch case atau / dan if...then. dengan menggunakan statement-statement control ini, aliran program secara praktis akan mudah dipahami dan dilacak jika terjadi kesalah logika (setiawan, 2006).

\subsection{Unity 3D}

Unity Aplikasi unity 3D adalah game engine merupakan sebuah software pengolah gambar, grafik, suara, input, dan lain-lain. yang ditujukan untuk membuat suatu game, meskipun tidak selamanya harus untuk game. Contohnya adalah seperti materi pembelajaran untuk simulasi membuat SIM. Kelebihan dari game engine ini adalah bisa membuat game berbasis 3D maupun 2D, dan sangat mudah digunakan. (Singkoh, 2016).

\subsection{GIMP}

GIMP adalah singkatan dari GNU Image Manipulation Program. Program ini merupakan program yang didistribusikan secara bebas untuk tugas - tugas seperti photo retouching, komposisi gambar, dan penulisan gambar.

\section{ANALISIS DAN PERANCANGAN}

\subsection{Analisis Game}

Merupakan analisis yang dilakukan melalui analisa game sejenis, analisa game yang akan dikembangkan, analisa algoritma, analisa kebutuhan fungsional, dan analisa kebutuhan non fungsional. Analisa game sejenis dilakukan dengan melakukan observasi langsung terhadap game-game sejenis. Analisa game yang akan dikembangkan merupakan analisis terhadap game yang akan dibangun. Analisa kebutuhan non fungsional merupakan analisa yang meliputi perangkat keras dan perangkat lunak yang digunakan. Analisa kebutuhan fungsional merupakan analisis game yang akan dibangun dengan 
menggunakan Artificial Intelligence atau kecerdasan buatan menerapkan metode Finite State Mechine (FSM) untuk mempermudah analisa kebutuhan dalam menentukan keseluruhan yang dibutuhkan secara lengkap, maka dibagi menjadi dua yaitu kebutuhan fungsional dan kebutuhan non fungsional.

\subsection{Analisis Kebutuhan}

Pada game Lastri and the Last Tree diperlukan perangkat keras maupun perangkat lunak untuk mengembangkan maupun memainkannya. Adapun kebutuhannya meliputi :

\subsubsection{Analisis Kebutuhan Perangkat Keras}

Dalam pembuatan aplikasi Media Pembelajaran Bahasa Jepang Level Dasar, perangkat keras yang digunakan adalah laptop dengan spesifikasi sebagai berikut:

a. Intel(R) Core(TM) i3-4010U CPU@ 1.70Ghz

b. 4GB RAM

c. VGA, NVIDIA geForce $740 \mathrm{M}$

3.2.2 Analisis Kebutuhan Perangkat Lunak

Selain hardware, software pendukung yang dipergunakan dalam perancangan aplikasi ini antara lain:

a. Sistem Operasi Windows 10 Pro 64-bit

b. Unity 3D

\subsection{Storyboard dan desai karakter}

A. Storyboard

Jalan cerita dari Game Lastri and the Last Tree ini menceritakan tentang keabakaran hutan yang sering terjadi dan penyebabnya belum pernah diketahi oleh masyarakat. Sampai pada suatu hari ada seorang anak bernama lastri yang berniat untuk menyelamatkan hutan yang terbakar, namun setelah sampai disana ternyata penyebab kebakaran yang terjadi adalah sekumpulan orang yang telah bermutasi sebagai zombie dan hanya tersisa satu pohon yang belum terbakar. Untuk menyelamatkan pohon tersebut lastri harus mengalahkan para zombie yang ada disana.

Dan tiap - tiap stage memiliki tingkat kesulitan yang berbeda pemain harus melewati bahkan membunuh NPC yang berupa zombie maupun rintangan - rintangan lain. Jika HP ( Health Point ) dari pemain tersebut nol, maka game akan terhenti dan muncul tulisan "Game Over".

\section{B. Desain Karakter}

Tabel Rancangan Desain Karakter

\begin{tabular}{|c|c|l|}
\hline No. & Karakter & \multicolumn{1}{c|}{ Keterangan } \\
\hline 1 & - & $\begin{array}{l}\text { Karakter utama yang } \\
\text { digunakan pada game. }\end{array}$ \\
\hline 2 & & $\begin{array}{l}\text { Karakter musuh level 1 } \\
\text { bernama odet yang } \\
\text { memiliki health 50. }\end{array}$ \\
\hline 3 & & $\begin{array}{l}\text { Karakter musuh level 2 } \\
\text { bernama ursa yang }\end{array}$ \\
\hline
\end{tabular}

\begin{tabular}{|c|c|l|}
\hline No. & Karakter & \multicolumn{1}{|c|}{ Keterangan } \\
\hline & & memiliki health 75. \\
\hline 4 & & $\begin{array}{l}\text { Karakter musuh level 3 } \\
\text { bernama ursula yang } \\
\text { memiliki health 100. }\end{array}$ \\
\hline 5 & $\begin{array}{l}\text { Karakter bos level 1 } \\
\text { yang bernama jarot } \\
\text { memiliki health 100 }\end{array}$ \\
\hline 6 & & $\begin{array}{l}\text { Karakter Bos level 2 } \\
\text { yang bernama belo } \\
\text { memiliki health 150. }\end{array}$ \\
\hline 7 & & $\begin{array}{l}\text { Karakter Bos level 3 } \\
\text { yang bernama jabrik } \\
\text { memiliki health 200. }\end{array}$ \\
\hline
\end{tabular}

Tabel Rancangan Desain Environmen

\begin{tabular}{|c|c|c|}
\hline No. & Item & Keterangan \\
\hline 1 & & $\begin{array}{l}\text { Platform beukuran } \\
\text { kecil. }\end{array}$ \\
\hline 2 & & $\begin{array}{l}\text { Platform berukuran } \\
\text { sedang }\end{array}$ \\
\hline 3 & & $\begin{array}{l}\text { Platform berukuran } \\
\text { besar. }\end{array}$ \\
\hline 4 & $\left(\gamma_{\text {HEA }}\right.$ & Healt bar untuk player \\
\hline 5 & ef & $\begin{array}{l}\text { Bibit sebagai reward } \\
\text { setiap kali mengalahkan } \\
\text { musuh }\end{array}$ \\
\hline 6 & & Backgroun pada level 1 \\
\hline 7 & & Backgroun pada level 2 \\
\hline 8 & , & Backgroun pada level 3 \\
\hline 9 & MMNMN & Rintangan pada level 1 \\
\hline 10 & 0000 & Rintangan pada level 2 \\
\hline
\end{tabular}

\subsection{Struktur Menu}

Pada game "Lastri and the Las Tree" terdiri dari beberapa menu yaitu Play Game, How to play, About, dan Exit. Diagram struktur menu dapat dilihat seperti pada gambar 3.1:

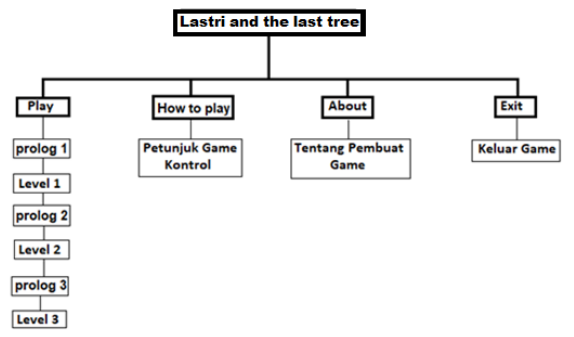

Gambar 3.1 Blok Diagram Sistem

Struktur menu menggambarkan isi pada menu game. pada menu play berisi level yang 
disediakan,pada menu about berisi biodata dan kontak pembuat game, pada menu how to play berisi bagaimana cara memainkan game dan pada menu exit untuk keluar dari game.

\subsection{Flowchart Game}

Pada perancangan flowchart game berfungsi untuk mengetahui alur proses dari alur dimulai start game hingga end game seperti pada gambar 3.2

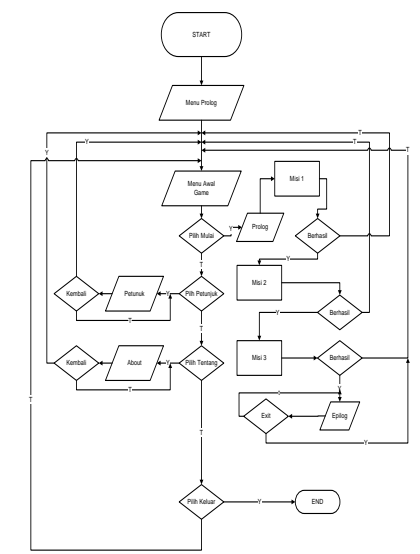

Gambar 3.2 Flowchart Sistem

Flowchart game menjelaskan alur dari game yang dikembangkan pada game play jika pemain ingin bermain harus menang level 1 agar bisa bermain pada level selanjutnya.

\subsection{Perancangan FSM pada musuh}

Finite State Machine merupakan salah satu logika penalaran yang memperlihatkan prilaku system dengan berdasarkan tiga hal, yaitu state (keadaan), event (kejadian), dan action (aksi). Pada suatu saat, system akan berada pada salah satu state yang aktif. Sistem dapat beralih atau bertransisi menuju state lain jika mendapatkan masukan atau event tertentu. Transisi keadaan ini umumnya juga disertai oleh aksi yang dilakukan oleh system ketika menanggapi masukan yang terjadi. Pada game Lastri and the Last Tree ini metode Finite State Machine diterapkan pada karakter musuh. Alur kecerdasan buatan Finite State Machineseperti gambar 3.4.

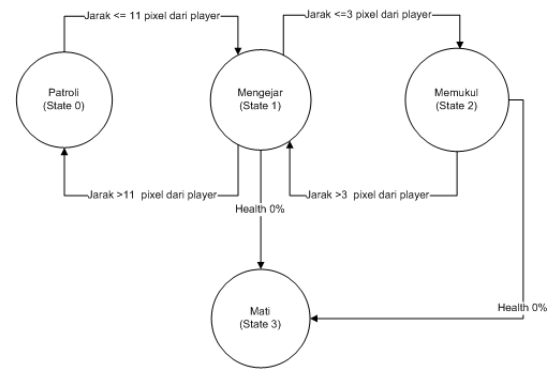

Gambar 3.4 Finite State Machine pada musuh.

Seperti yang terlihat pada Gambar 3.4, ketika sistem dijalankan maka sistem mula-mula berada pada state 0 (Bergerak atau patroli), jika player pada jangankauan enemy (jarak $\leq 11$ pixel) maka state 1 (Mengejar) akan dijalankan dan ketika player berada pada jarak (>11 pixel) maka musuh akan kembali pada state 0 atau kembali berpatroli. Jika berada musuh pada jangkauan player (jarak $\leq 3$ pixel) maka state 2 (Memukul) dan ketika player berada pada jarak (>3 pixel) maka musuh akan kembali pada state 1 atau kembali mengejar dan ketika health bar enemy mencapai $0 \%$ maka state 3 (Mati) akan dijalankan.

\section{IMPLEMENTASI DAN PENGUJIAN}

4.1. Implementasi script ke player dan karakter

Implentasi script pada player bertujuan agar player dapat di kontrol oleh pemain. Kontrol pada player dapat berupa bergerak, melompat, menyerang, dan sebagainya.

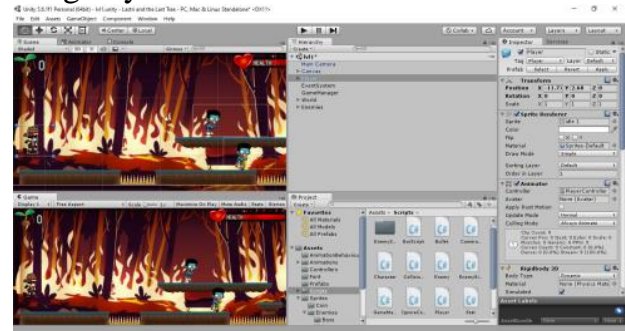

Gambar 4.1 Implentasi Player dan karakter enemy

Pada gambar $4.1 \quad$ merupakan pengimplementasian script pada player dan karakter enemy, ditambahkan karakter ke dalam unity 5.6.1 dan ditambahkan script agar bisa bergerak sesuai yang diingikan oleh pengembang.

\subsection{AI pada musuh}

AI pada musuh merupakan agar musuh dapat berperilaku ketika ada aksi dari player. Misal player berada pada jarak tertentu maka aksi dari musuh bisa berupa mengejar, menyerang dan sebagainya sesuai aksi yang telah di terapkan pada musuh. Untuk implementasi musuh dapat di lihat pada Gambar 4.2.

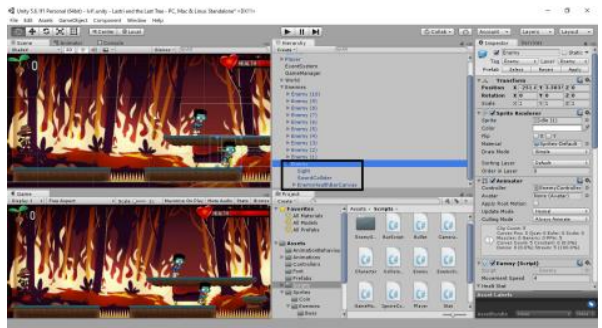

Gambar 4.2 AI pada Musuh

\subsection{Tampilan Menu Utama}

Tampilan menu utama adalah tampilan awal yang akan muncul pada saat pemain menjalankan Game Adventure "Lastri And The Last Tree". Pada tampilan awal ini berisikan tombol Play, how to play, about, Exit. Play untuk memulai game baru, tombol How to play berisi cara controller player, tombol About berisikan tentang creator game dan tombol exit 
untuk keluar dari game. Tampilan menu utama seperti Gambar 4.3.

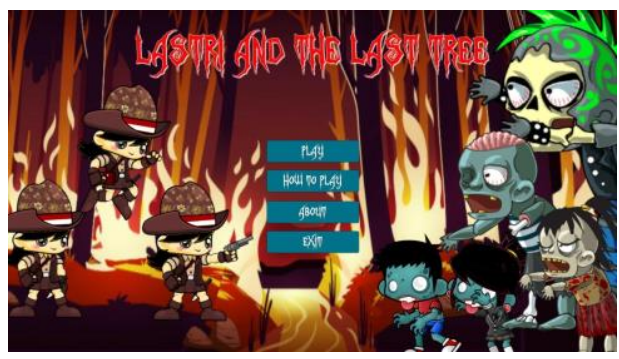

Gambar 4.3 Tampilan Menu Utama

\subsection{Tampilan How To Play}

Tampilan How To Play adalah menu untuk mengetahui fungsi tombol yang akan digunakan pada Game Adventure "Lastri And The Last Tree", tampilan dari menu How To Play seperti pada gambar 4.4

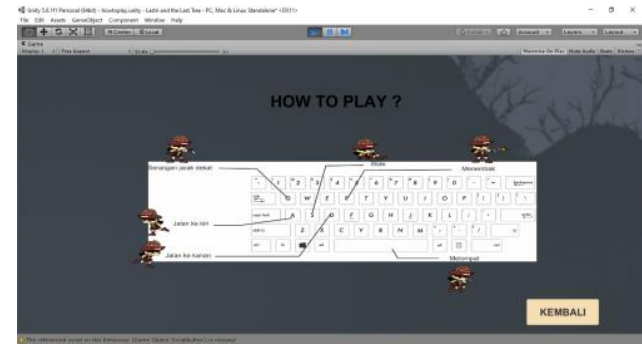

Gambar 4.4 Tampilan menu How To Play

\subsection{Tampilan About}

Tampilan menu About adalah tampilan menu untuk mengetahui profil pembuat Game Adventure "Lastri And The Last Tree", tampilan dari menu About seperti Gambar 4.5

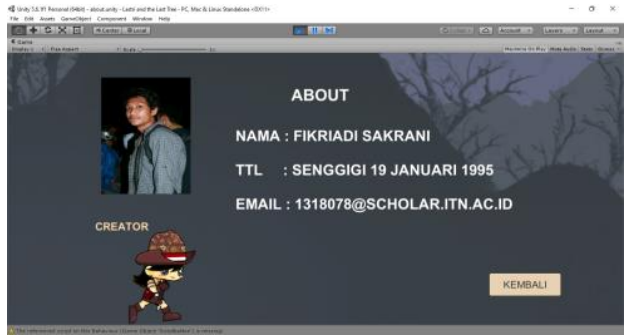

Gambar 4.5 Tampilan menu About

\subsection{Tampilan Prolog}

Tampilan prolog adalah tampilan yang menjelaskan alur cerita pada setiap levelnya dan prolog ini akan muncul di setiap awal level. Tampilan prolog pada level 1 dapat dilihat pada gambar 4.6

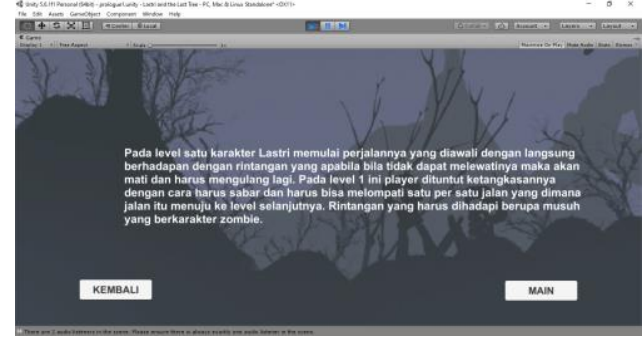

Gambar 4.6 Tampilan Prolog level 1

Tampilan prolog level 2 mempunyai background dan alur cerita yang berbeda dan mempunyai satu button untuk melanjutkan ke game level 2 dapat dilihat seperti pada gambar 4.7

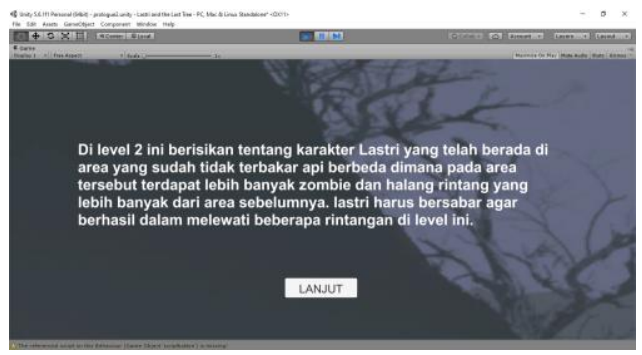

Gambar 4.7 Tampilan prolog level 2

Tampilan prolog level 3 dengan background yang lebih gelap dan akan muncul setelah menyelesaikan game level 2 dapat dilihat seperti pada gambar 4.8.

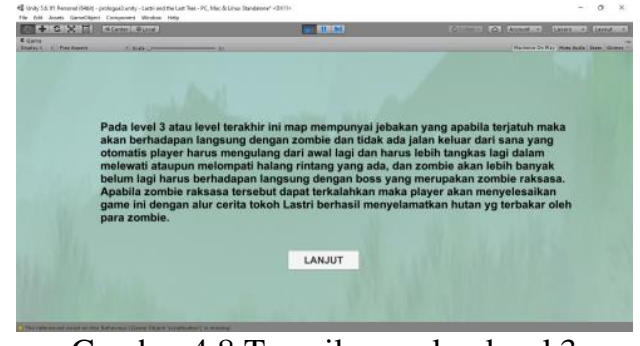

Gambar 4.8 Tampilan prolog level 3

\subsection{Tampilan Gameplay}

Tampilan gameplay pada setiap level yang menampilkan permainan petualangan aksi dengan menghadapi musuh-musuh dan melawan enemy untuk ke level selanjutnya. Tampilan gameplay pada level 1 dapat di lihat seperti pada Gambar 4.9

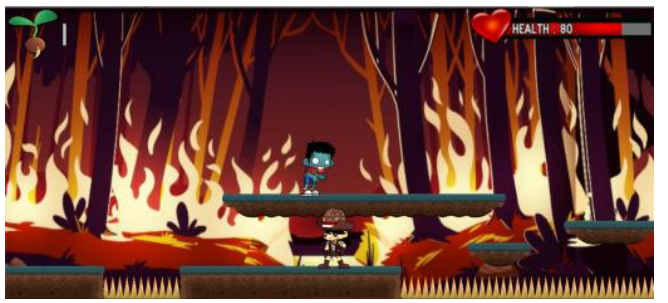

Gambar 4.3 Tampilan Gameplay Level 1 
Tampilan gameplay level 2 yang mempunyai latar belakang tanah yang berbeda dengan level 1 dapat dilihat seperti pada gambar 4.10

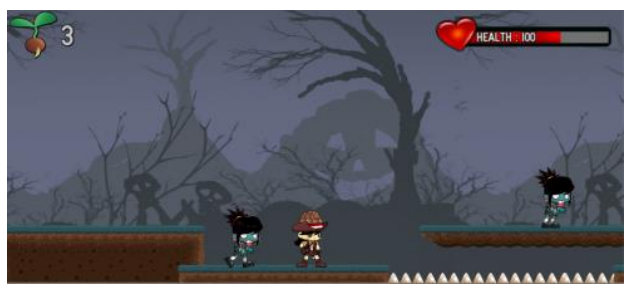

Gambar 4.4 Tampilan Gameplay Level 2

Tampilan gameplay level 3 yang mempunyai latar belakang tanah lebih gelap yang menandakan sudah mendekati permukaan tanah yang dapat dilihat seperti pada gambar 4.11

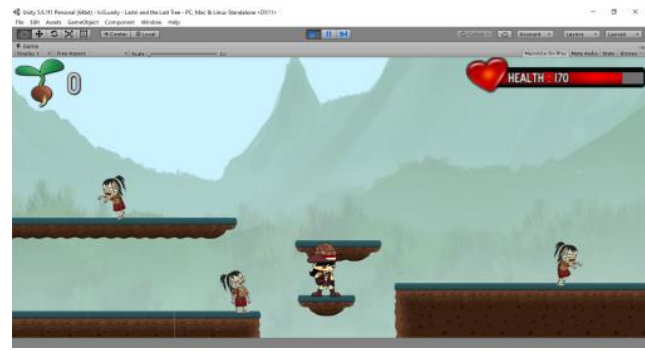

Gambar 4.5 Tampilan Gameplay Level 3

\subsection{Pengujian AI (Artificial Intelligence)}

Pengujian artificial intelligence adalah pengujian mengenai fungsi yang berkaitan dengan artificial intelligence yang ada pada Game Petualangan "Lastri And the Last Tree". Hasil pengujian dari artificial intelligence pada game ini seperti pada table 4.1

Tabel 4.1 pengujian AI

\begin{tabular}{|c|c|c|c|c|}
\hline No & Status & Event & Action & Hasil \\
\hline 1 & Berpatroli & $\begin{array}{c}\text { Jika player } \\
\text { tidak } \\
\text { menjagkau } \\
\text { sight karakter } \\
\text { enemy }\end{array}$ & $\begin{array}{c}\text { Maka enemy } \\
\text { pada posisi } \\
\text { diam }\end{array}$ & sesuai \\
\hline 2 & Berpatroli & $\begin{array}{c}\text { Jika player } \\
\text { tidak } \\
\text { menjangkau } \\
\text { enemy dengan } \\
\text { jangka waktu } 5 \\
\text { detik }\end{array}$ & $\begin{array}{c}\text { Maka enemy } \\
\text { pada posisi } \\
\text { patrol }\end{array}$ & sesuai \\
\hline 3 & Berpatroli & $\begin{array}{c}\text { Jika player } \\
\text { menjangkau } \\
\text { sight enemy } \\
\text { dengan jarak } 11 \\
\text { pixel }\end{array}$ & $\begin{array}{c}\text { Maka enemy } \\
\text { akan } \\
\text { mengejar }\end{array}$ & sesuai \\
\hline 4 & Berpatroli & $\begin{array}{c}\text { Jika player } \\
\text { menjangkau } \\
\text { sight enemy } \\
\text { dengan jarak } 5 \\
\text { pixel }\end{array}$ & $\begin{array}{c}\text { Maka enemy } \\
\text { akan } \\
\text { menyerang }\end{array}$ & sesuai \\
\hline
\end{tabular}

\begin{tabular}{|c|c|c|c|c|}
\hline No & Status & Event & Action & Hasil \\
\hline 5 & Berpatroli & Jika player \\
& & $\begin{array}{c}\text { Maka enemy } \\
\text { berjarak lebih } \\
\text { dari }>11 \text { pixel } \\
\text { dari enemy }\end{array}$ & $\begin{array}{c}\text { posuai } \\
\text { posisi idle } \\
\text { dan patroli }\end{array}$ & \\
& & & \\
\hline
\end{tabular}

\subsection{Pengujian Fungsional}

Pengujian fungsioanal adalah pengujian mengenai proses fungsioanal yang terjadi dalam game. hasil pengujian dapat dilihat pada tabel 4.2

Tabel 4.2 Pengujian Fungsional

\begin{tabular}{|c|c|c|c|}
\hline \multirow{2}{*}{ No } & Item Uji & \multicolumn{2}{|c|}{ Hasil } \\
\cline { 3 - 4 } & Berhasil & Gagal \\
\hline 1 & Menu Utama & $\sqrt{ }$ & - \\
\hline 2 & Button Star & $\sqrt{ }$ & - \\
\hline 3 & Button Instruktion & $\sqrt{ }$ & - \\
\hline 4 & Buton Exit & $\sqrt{ }$ & \\
\hline 5 & Level 1 game & $\sqrt{ }$ & - \\
\hline 6 & Level 2 game & $\sqrt{ }$ & - \\
\hline 7 & Level 3 game & $\sqrt{ }$ & - \\
\hline 8 & Bar Health poin Player & $\sqrt{ }$ & - \\
\hline 9 & $\begin{array}{c}\text { Bar Health poin } \\
\text { Musuh }\end{array}$ & $\sqrt{ }$ & - \\
\hline 10 & Animasi pada Game & $\sqrt{ }$ & - \\
\hline 11 & $\begin{array}{c}\text { Hp musuh berkurang } \\
\text { ketika terkena } \\
\text { seranagan }\end{array}$ & $\sqrt{ }$ & - \\
\hline 12 & $\begin{array}{c}\text { Hp player berkurang } \\
\text { ketika terkena } \\
\text { serangan }\end{array}$ & $\sqrt{ }$ & - \\
\hline 13 & $\begin{array}{c}\text { Musuh meyerang pada } \\
\text { jarak tertentu }\end{array}$ & $\sqrt{ }$ & - \\
\hline 14 & $\begin{array}{c}\text { Musuh berjaga pada } \\
\text { jarak tertentu }\end{array}$ & $\sqrt{ }$ & \\
\hline 16 & $\begin{array}{c}\text { Game tamat ketika HP } \\
\text { player 0\% }\end{array}$ & $\sqrt{ }$ & - \\
\hline
\end{tabular}

\subsection{Pengujian Control Player}

Pengujian control player adalah pengujian setiap fungsi dari tombol yang sudah diterapkan untuk menggerakan karakter utama. Hasil pengujian player pada table 4.3

Table 4.3 Pengujian Control

\begin{tabular}{|l|c|l|l|}
\hline No. & $\begin{array}{l}\text { Tomb } \\
\text { ol }\end{array}$ & Action & Hasil \\
\hline 1. & A & Karakter bergerak ke Kiri & Sesuai \\
\hline 2. & D & Karakter bergerak kanan & Sesuai \\
\hline 3. & Spasi & Lompat & Sesuai \\
\hline 4. & $S$ & Slide & Sesua \\
\hline 5. & $Q$ & $\begin{array}{l}\text { Karakter menguluarkan } \\
\text { pisau }\end{array}$ & Sesuai \\
\hline 6. & $R$ & $\begin{array}{c}\text { Karakter mengeluarkan } \\
\text { tembakan }\end{array}$ & Sesuai \\
\hline
\end{tabular}

Dari tabel 4.3 ketika pemain menekan tombol huruf A, D, spasi, S, R, dan Q bergerak sesuai 
dengan fungsinya.Huruf A untuk bergerak ke arah kiri, huruf D untuk bergarak ke arah kanan, space untuk meloncat, $S$ untuk slide, R untuk menembak. Dan untuk melakukan serangan menggunakan tombol Q. Dari penjelasan diatas menunjukan bahwa semua fungsi dari kontrol berjalan sesuai dengan fungsinya dengan tingkat keberhasilan mencapai $100 \%$.

\subsection{Pengujian User}

Pengujian dilakukan untuk mengetahui apakah sistem sudah berjalan dengan baik atau belum. Pengujian dilakukan terhadap 13 responden yang merupakan pecinta game atau gamers. Hasil dari pertanyaan terhadap responden dapat dilihat pada tabel 4.4

Table 4.4 Pengujian User

\begin{tabular}{|l|l|c|c|c|}
\hline $\begin{array}{l}\text { No } \\
.\end{array}$ & pertanyaan & B & C & K \\
\hline 1 & $\begin{array}{l}\text { Apakah tampilan karakter } \\
\text { pada game menarik? }\end{array}$ & 9 & 4 & 0 \\
\hline 2 & $\begin{array}{l}\text { Apakah game yang dimainkan } \\
\text { menantang dan menarik? }\end{array}$ & 11 & 2 & 0 \\
\hline 3 & $\begin{array}{l}\text { Apakah controler pada game } \\
\text { nyaman digunakan? }\end{array}$ & 8 & 4 & 1 \\
\hline 4 & $\begin{array}{l}\text { Apakah tombol controller } \\
\text { telah sesuai dengan } \\
\text { fungsinya? }\end{array}$ & 11 & 2 & 0 \\
\hline 5 & $\begin{array}{l}\text { Apakah pesan yang } \\
\text { terkandung dalam game } \\
\text { tersampaikan? }\end{array}$ & 9 & 4 & 0 \\
\hline 6 & $\begin{array}{l}\text { Apakah AI pada musuh } \\
\text { berjalan tanpa kendala? }\end{array}$ & 10 & 3 & 0 \\
\hline
\end{tabular}

\section{PENUTUP}

\subsection{Kesimpulan}

Setelah pembuatan Game Lastri And the Last

Tree, maka penulis dapat mengambil kesimpulan:

1. Penerapan metode FSM (Finite State Machine) pada game 2 dimensi bergenre adventure (Lastri And the Last Tree), dengan indikasi musuh dapat mengejar dan menyerang player dengan jarak $<11$ pixel dalam Unity.

2. Semua fungsi tombol control player berjalan dengan tingkat keberhasilan 100\%.
3. Game Lastri And The Last Tree ini menerapkan FSM (Finite State Machine) pada musuh kecil dan Boss

4. Pengujian $A I$ menggunakan metode FSM (Finite State Machine) didapat hasil yang sesuai, seperti musuh dapat bergerak dengan otomatis sesuai dengan kecederdassan buatan yang diterapkan.

5. Pengujian User yang telah dilakukan pada 13 oran mendapatkan timbal balik yang cukup baik.

\subsection{Saran}

Setelah dilakukan pengujian terhadap Game Lastri And The Last Tree maka masih ada kekurangan sehingga untuk pengembangan lebih lanjut disarankan :

1. Dapat dikembangkan sebagai mobilegame berbasis platform android dan ios atau versi webnya.

2. Dapat di tambah jumlah Levelnya.

3. Dapat di tingatkan kualitas grafiknya

4. Dapat di tambahkan item-item dan rintangan yang lebih banyak.

\section{DAFTAR PUSTAKA}

[1] Irawan, J.D, dkk, 2015, Pelatihan Pembuatan Game Menggunakan Greenfoot. Industri inovatif Vol. 5, No. 2, 29 - 35.

[2] Wahyuni F.S dan Mantja S.N, 2016, Penerapan Algoritma A* Untuk Pencarian Rule Terdekat Pada Permainan Berbasis Ubin (Tile Base Game). SENIATI 2016 B.168-172

[3] Pratama, W., 2014. Game Adventure Misteri Kotak Pandora. Telematika, 7(2).

[4] Edi Wijaya., 2013. Analisis Penggunaan Algoritma Breadth First Search Dalam Konsep Artificial Intellegencia, Jurnal Time Vol. 2, No.2, 18 - 26.

[5] Rahadian, M.F., Suyatno, A. and Maharani, S., 2017. PENERAPAN METODE FINITE STATE MACHINE PADA GAME "THE RELATIONSHIP”.

[6] Arsawiguna, M. G., Wiranatha, A. K. A. C., and Wibawa, K. S. 2015. Rancang Bangun Aplikasi Game Tajen Berbasis Android menggunakan Artificial Intelligence. Lontar Komputer: Jurnal Ilmiah Teknologi Informasi, 84-95. 